Article

\title{
Reading Alexander V. Choate Rightly: Now is the Time
}

\author{
Leslie Francis ${ }^{1, *}$ and Anita Silvers ${ }^{2}$ \\ 1 Department of Philosophy and S.J. Quinney College of Law, University of Utah, Salt Lake City, \\ UT 84112, USA \\ 2 Department of Philosophy, San Francisco State University, San Francisco, CA 94132, USA; asilvers@sfsu.edu \\ * Correspondence: francisl@law.utah.edu
}

Received: 10 August 2017; Accepted: 21 September 2017; Published: 8 October 2017

\begin{abstract}
Whatever happens to the Affordable Care Act (ACA) over the next few years, it is fair to assume that state Medicaid programs will be subjected to cost control measures. Despite the recent deployment of substantial arguments to the contrary, the belief still persists that the Supreme Court's decision in Alexander v. Choate over thirty years ago stands for the proposition that disability anti-discrimination law does not impose requirements on the structure of Medicaid benefits. This belief is misleading at best. In this article, we challenge the access/content distinction and the straitened interpretation of Alexander v. Choate that has resulted from it. We then use cases drawn from education to point the way to a more robust analysis of meaningful access to health care and the constraints it places on the design of state Medicaid programs.
\end{abstract}

Keywords: disability; discrimination; meaningful access; health care; Alexander v. Choate; justice

Whatever happens to the Affordable Care Act (ACA) over the next few years, it is fair to assume that state Medicaid programs will be subjected to cost control measures. Despite the recent deployment of substantial arguments to the contrary, the belief still persists that the Supreme Court's decision in Alexander $v$. Choate ${ }^{1}$ over thirty years ago stands for the proposition that disability anti-discrimination law does not impose requirements on the structure of Medicaid benefits. This belief is misleading at best.

Given the importance of the Medicaid program to so many, including many people with disabilities, it is critical that this wrong reading be put to rest. In this essay, we explain that Alexander v. Choate sets clear limits to decisions states may make in the design of their Medicaid programs. "Meaningful access" is the standard from which these inhibitions on how states may constrain their programs derive. Taking the "meaningful access" standard into proper account will be critical as state Medicaid programs respond to calls for revision.

\section{Challenges to State Medicaid Programs}

State Medicaid programs face many problems in funding the care they provide. These include increasing numbers of people qualifying for the program, expanded eligibility, and increases in the costs of health care. States face other pressure on resources as well, such as declining tax revenues, increases in the costs of other state services, and the need to address deferred infrastructure repairs.

State Medicaid programs play a critical role in the provision of health care in the US today. According to the latest data from the Centers for Medicare and Medicaid services, over 72 million people are covered by Medicaid at any given time (CMS.gov. 2017). Even more are covered at some point in time during a given year. Just about one quarter of Medicaid enrollees are the elderly and people with disabilities;

$1 \quad$ Alexander v. Choate, 469 U.S. 287 (1985). 
these beneficiaries, who are eligible for traditional Medicaid, account for nearly two-thirds of Medicaid spending (The Kaiser Commission on Medicaid and the Uninsured 2016). A major expenditure category under the Medicaid program is long term care; the numbers of the elderly in need of such care continue to increase.

Including the District of Columbia, 32 states have adopted the Medicaid expansion made available by the ACA (Snyder and Rudowitz 2016). Under this expansion, non-elderly adults with incomes up to $138 \%$ of the federal poverty level became eligible for Medicaid. According to the National Council on Disability, the Medicaid expansion extended coverage to many adults with more moderate disabilities who did not qualify for Social Security Disability Income (National Council on Disability 2016). With or without the ACA expansion, over the years a variety of demonstration projects have enabled some states to expand coverage, primarily to pregnant women and children but also to some others.

Over 10 million of those covered by Medicaid are people who come within traditional Medicaid's categorical eligibility for people with disabilities (CMS.gov. 2017). In addition, nearly 6 million Medicaid recipients are aged. The aged, blind, and disabled are categorically eligible under traditional Medicaid, so people in these categories may receive Medicaid even in states that did not take advantage of the ACA expansion. Medicaid is especially useful for people with disabilities because it has more extensive benefits than many private plans (National Council on Disability 2016). Long term care coverage is a particularly important example of a benefit available under Medicaid but not under typical private plans. Nursing home care is one of the largest single expenditure types in the Medicaid budget; Medicaid pays for 6 in 10 of all nursing home residents in the United States (Kaiser Family Foundation 2017). Nonetheless, in some states people in the expansion population received benefits modeled on private plans rather than traditional Medicaid.

The American Recovery and Reinvestment Act of 2009 limited states' ability to control costs through changes to eligibility standards or enrollment processes (Snyder and Rudowitz 2016). This has increased pressure to turn to benefit limitations and provider reimbursements as alternative cost control measures.

Medicaid gives states a great deal of flexibility to set reimbursement rates for providers, so long as the rates are "consistent with efficiency, economy and quality of care and sufficient to enlist enough providers so that care and services are available under the plan at least to the extent they are available to the general population in the geographical area." ${ }^{2}$ Whether this standard is met is the subject of frequent controversy, especially when the numbers of beneficiaries are expanding. Faced with the alternative of going out of business, Medicaid providers such as habilitation services facilities may continue to accept patients despite what they claim are inadequate payment rates. In addition, they may cut staffing or otherwise compromise the quality of services (Kaiser Family Foundation 2017). A 2015 Supreme Court decision held that providers do not have a cause of action to challenge these state reimbursement decisions. ${ }^{3}$ The practical result of this decision is to leave it to the federal Department of Health and Human Services to decide whether to challenge the adequacy of state reimbursement rates (Rosenbaum 2015).

An irony of Medicaid financing is that needs grow when revenue contracts. When the economy slows, people may become unemployed and thus need to turn to public programs for whatever health coverage might be available. But Medicaid is financed from tax revenues, in a federal/state matching mix, and a contracting economy brings contracting tax revenues. Revenues may be slow to recover, as they have been since the recession of 2007-2009 (Kaiser Family Foundation 2016). Given the reality of state budgets-all states except Vermont have balanced budget requirements (National Conference of State Legislatures 2013), many states have underfunded pension obligations (Baldwin 2016), infrastructure such as roads and bridges is crumbling, and costs of programs such as

42 U.S.C. $\S 1396 a(a)(30)(A)(2017)$.

Armstrong v. Exceptional Child Center, Inc., 135 S. Ct. 1378 (2015). 
education or corrections continue to rise-pressures on Medicaid will not abate even as revenues rise. And there is the reality of Congressional threats to change the structure of Medicaid to block grants or some other funding structure that will reduce federal revenues available to the program.

State Medicaid programs thus face clear financial challenges. These challenges cannot be expected to dissipate in the near future. As we now shall show, assuming that these challenges can be resolved free of limits set by disability anti-discrimination law is deeply problematic.

\section{Alexander v. Choate: A Legacy of Misunderstanding}

In 1980, Tennessee faced a projected shortfall of over $\$ 40$ million in its Medicaid budget. To address the shortfall, the program reduced the yearly number of inpatient hospital days for Medicaid patients from 20 to $14 .{ }^{4}$ Medicaid patients challenged the limit as discrimination against the handicapped in violation of $\S 504$ of the Rehabilitation Act. The Supreme Court rejected the challenge. In so doing, the Court rejected the contention that $\S 504$ should be understood to prohibit any action disproportionately disadvantaging people with disabilities. Such a standard would create "a wholly unwieldy administrative and adjudicative burden. ${ }^{5}$ People with disabilities are not similarly situated to others, so it is likely that programs will affect them differently. But not all differences are permissible; the Court applied the standard of "meaningful access" as a test for determining when a difference is disability discrimination. ${ }^{6}$ A state would violate the Rehabilitation Act, the Court said, if people with disabilities did not have meaningful access to a benefit that the state made available to others. Tennessee did not have to provide any particular health benefits, or health benefits at all, so long as if it provided benefits to some while providing meaningful access to those benefits to persons with disabilities. And, the Court found in holding for the state there was no evidence that Tennessee had failed to provide such access to people with disabilities. ${ }^{7}$

A common reading of Alexander $v$. Choate is that it gives states freedom to design the Medicaid benefits they offer, at least so far as anti-discrimination law is concerned. States might choose not to fund inpatient hospital stays at all, or only to fund a limited number of days. This reading is understandable. In the decision, the Court says that the Rehabilitation Act considered substantive areas where "the societal and personal costs of refusals to provide meaningful access" were particularly high. ${ }^{8}$ These areas were employment, education, and the elimination of physical barriers to access. With regard to state provided health insurance, however, "nothing in the pre- or post-1973 legislative discussion of $\S 504$ suggests that Congress desired to make major inroads on the States' longstanding discretion to choose the proper mix of among, scope, and duration limitations on services covered by state Medicaid." ${ }^{9}$

In his highly influential scholarship on the ADA, Samuel Bagenstos construes this reasoning as introducing what he terms the "access/content distinction (Bagenstos 2009)." States may choose the benefits included in the package they provide; this is the content side of the distinction. Once the state has decided on the contents of its benefits package, however, it cannot give access to some while others remain without access that is meaningful. This is the access side of the distinction. According to Bagenstos, this leaves states with considerable freedom to maneuver in structuring their Medicaid programs: as long as they frame a program change in terms of the benefits offered, rather than as a change in eligibility requirements for participation in the program, they are not engaging in prohibited discrimination.

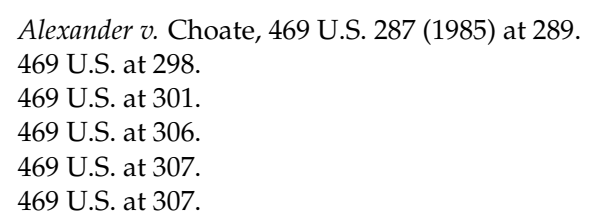


Bagenstos situates this distinction in the context of a far-reaching tension in disability rights between ending discrimination and overcoming structural barriers. It is discriminatory for some to have access to a benefit that others do not when the difference is based on disability. This is the approach of anti-discrimination law, Bagenstos says. However, this understanding of anti-discrimination law narrows its scope to the questions of whether like cases are treated alike with respect to accessing a specified benefit (See, e.g., (Minow 1991)) Minow, Martha. 1991. Making all the Difference: Inclusion, Exclusion, and American Law. Ithaca: Cornell University Press. ${ }^{10}$ On Bagenstos's formulation of the access/content distinction, access has no further purchase beyond this formal sense. Justifications such as promoting inclusion of people with disabilities in societies that have proved unwelcoming to them or providing a safety net to meet disabled people's basic needs call for foundations beyond this narrow requirement of treating like cases alike.

Bagenstos does point out that the access/content distinction is subject to manipulation. ${ }^{11}$ If the benefit at issue is delineated more broadly, for example as access to needed surgery, access differences will surface. People who cannot get needed surgery within 14 days, but could without a cap on hospital reimbursement, will lack access in any practical sense to needed surgery. If the benefit is specified more narrowly, however, such as 14 hospital days, access differences will disappear as this benefit will be available to all. Bagenstos further contends that courts will be inclined to define benefits narrowly so that they do not confront difficult questions about access. In developing this argument, Bagenstos primarily relies on analysis of the accommodation requirement in employment discrimination cases. This is a requirement that is especially inviting to narrow construction. If the accommodation requirement is construed narrowly, courts will be able to avoid difficult judgments about whether proposed accommodations are reasonable and whether they impose undue hardships on employers. ${ }^{12}$

Thus understood, the access/content distinction would appear to offer a ready way to generate a narrow reading of Alexander $v$. Choate. In introducing the distinction, the Court is clearly eager to avoid any suggestion that courts should move into the business of managing state health care decisions. Whether the states must provide everyone with adequate health care, a decent minimum of health care-much less what either of these might mean—is a different question than whether the Medicaid programs states provide must be free of discrimination against people with disabilities. This point is fundamental to the Court's analysis. But avoiding disputes about the adequate level of benefit does not entail that content requirements are altogether free of antidiscrimination scrutiny. Nor does it entail that access requirements are limited to whether all those similarly situated can access the same benefit, however the benefit is specified.

In an earlier article, we countered this deployment of the access/content distinction. ${ }^{13}$ Our argument was that the Court had modified access in a critical way: access had to be "meaningful access," not just access. Access in name only is not meaningful. Nor is access to something that is unusable or intrinsically of no use to persons eligible for the service or benefit, such as binoculars for the blind.

This qualification that access must be meaningful, we said, imposes a substantive standard on access: that it provides everyone with a fair opportunity to enjoy the benefit. If some can do a great deal with the benefit, and others cannot make use of it at all or only minimally, access for the latter group is not meaningful. As examples, we used durable medical equipment and services for the chronically mentally ill. Health plans without coverage for durable medical equipment, we contended,

10 Like Martha Minow and many others, we reject this Aristotelian way of characterizing anti-discrimination law as purely a matter of formal justice. When people are both similar and different in multiple ways that may be potentially relevant to justice, the critical questions are what makes like cases alike and what makes types of treatment similar.

11 Contradictions at 73-74.

12 42 U.S.C. $\S 12112(\mathrm{~b})(5)(\mathrm{A})$.

13 [footnote omitted to preserve anonymity]. 
are not programs that offer meaningful access to health care, as people cannot use health care in a way that benefits them without the durable medical equipment they need.

In concluding that the 14-day limit on payment for inpatient hospitalizations did not discriminate based on disability, the Court had not said that people with disabilities had access to that benefit because Medicaid would pay for that number of days for them on the same terms as for others. Rather, the Court had said that challengers to the 14-day limit had not shown that people with disabilities were so disproportionately unable to get the hospital care they needed because of the limit, when other people could get that care, that the difference amounted to discrimination. In the Court's language: "Moreover, it cannot be argued that "meaningful access" to state Medicaid services will be denied by the 14-day limitation on inpatient coverage; nothing in the record suggests that the handicapped in Tennessee will be unable to benefit meaningfully from the coverage they will receive under the 14-day rule. The reduction in inpatient coverage will leave both handicapped and nonhandicapped Medicaid users with identical and effective hospital services fully available for their use, with both classes of user subject to the same durational limitation."14 To sum up the Court's point: patients must be similarly able to use their hospital days effectively, or they do not have meaningful access to them.

Nonetheless, the significance of this "meaningfulness" qualifier has been under appreciated. Commentators have instead continued to follow the crabbed reading of "meaningful access" reflected in the Bagenstos interpretation of the access/content distinction. Instead of exploring what substantive standards a requirement that access be meaningful might impose on state Medicaid programs, they have sought to draw on other sources to define what makes access meaningful. If these other sources are unstable or change, however, they may no longer be available to help in defining meaningfulness.

Mary Crossley recently explored the implications of the access/content distinction for challenging the introduction of managed care programs into Medicaid (Crossley 2014). These programs, when implemented for all Medicaid patients, pose potential access problems for people with disabilities. Their initial use was directed primarily to coverage for pregnant women and children, a population for which preventive care needs were central. Their success for this population, however, cannot be generalized to the more complex medical problems that arise for some people with disabilities or for people eligible for both Medicare and Medicaid. Crossley considers whether members of this population might be able to argue that they lacked meaningful access to Medicaid under managed care.

There are several ways in which this might be so: for example, that enrollment processes are difficult to use for people with intellectual disabilities or that providers in the managed care network lack accessible medical equipment that can be used by people with physical disabilities. These are classic cognitive or physical access barriers; although important, they do not address more general concerns that managed care networks will not provide people with disabilities with access to the specialists or types of care that they need. Here, Crossley judged that the access/content distinction in Alexander v. Choate presents a "real problem." ${ }^{15}$ It blocks the argument that disabled beneficiaries are not benefiting as much from their Medicaid benefits as others are. As a solution, she resorts to the suggestion that beneficiaries use the language of state waiver applications to determine the content of the meaningful access standard. ${ }^{16}$ Crossley writes: "Framing the claim to incorporate the state's own representations should help plaintiffs avoid a characterization-fatal under Choate- that they are simply complaining that the benefit the state has chosen to provide does not fully meet their more complex medical needs. Instead, plaintiffs can argue that a state's failure to live up to its own access-related commitments keeps disabled plaintiffs from enjoying the same chance as other Medicaid recipients to benefit from enrollment in a Medicaid managed care plan."17 
Crossley's suggested approach relies on the language of waiver applications. In these applications, she contends, the state lays out its own standard for what makes access meaningful and can therefore be held to that standard. However, to the extent that waiver applications do not contain representations about access—or, if waiver applications are no longer required at all—Crossley's suggested approach will no longer be available. Thus it is important to note a gap in Crossley's argument that leads her to the suggestion she makes. She judges that the access/content distinction in Alexander $v$. Choate blocks a challenge that disabled beneficiaries are not benefiting as much from their Medicaid as are abled beneficiaries. Even if this challenge is blocked because Alexander $v$. Choate rejects as a test whether benefits are adequate to meet the health care needs of people with disabilities fully, it does not follow that meaningful access standards cannot have substantive content.

In another recent article, Valarie Blake explores a different approach to disability discrimination in state Medicaid programs (Blake 2017). Like Crossley, she assumes that the access/content distinction is a fatal barrier. She writes, "antidiscrimination laws only provide people with disabilities with the ability to access a program, not the right to challenge its content. Any effort to argue for better or different benefits is viewed as a 'fundamental alteration' to a program which is an affirmative defense for insurers." 18 Instead, Blake argues that the non-discrimination provisions in the ACA abrogate the access/content distinction and thus provide a different legal basis for challenging state Medicaid limitations. If these restrictions in the ACA are changed, however-which remains a very real possibility-this strategy will evaporate. Like Crossley, Blake also draws an unwarranted inference from Alexander $v$. Choate's rejection of scrutiny of the adequacy of benefits. The inference she makes is that any argument for different benefits—even one based on standards of meaningful access—must be barred by the defense that it is a fundamental program alteration.

To take one final example, in a very helpful article forthcoming in the Cardozo Law Review, Mark Weber argues that courts make better decisions in meaningful access cases when they employ empirical evidence about the actual impacts on people with disabilities (Weber). Weber writes: "Whether a person or class of persons has meaningful access to a government service is fundamentally an empirical question. How great a negative effect does a government decision have to have on people with disabilities in order to deny meaningful access? For a class-based claim like that in Choate challenging cutbacks in government benefits, a number of social research questions would be relevant: How many persons with disabilities are affected, how many experience a complete denial of services, how many suffer partial denials of services or the need to make do with inappropriate services that nevertheless confer some benefit, what losses do the complete and partial denials of services cause, what substitute services are offered, and how effective are the substitutes in comparison to the beneficiaries' needs?" Weber then turns to how some courts have used social science evidence to answer these questions, while other courts have not.

Weber clearly is right about the importance of social science evidence in these discussions and the problematic effect of its absence. For example, our earlier article pointed out the paucity of the record in Alexander $v$. Choate on the very question of whether people with disabilities in Tennessee had been unable to receive needed treatments such as surgeries at all because of the new limitation. However, his discussion draws the problematic conclusion that courts should defer to triers of fact to resolve the question. These are not only empirical questions, but also normative ones. We surely need to know how many people experience a complete denial of services-for example, how many people subjected to a 14-day limit on paid hospital days cannot receive surgery at all, because physicians will not operate on them due to their recovery predictably requiring a hospital stay of more than 14 days.

We also need to know whether the surgery is sufficiently important that its denial constitutes a denial of meaningful access to care. Otherwise, the constrained construction of the access/content distinction can reemerge in the form of a finding that few, if any, people with disabilities were unable

18 Blake at 203. 
to access the benefit of 14 hospital days, a finding that could make irrelevant whether the 14 days they could access were meaningful given their health needs. Weber's own example from health care, of cases challenging limitations on home and community based services, is an illustration. The problem for many people with disabilities is that without these services people may be unable to continue to live in the community. Empirical evidence will surely help in understanding the frequency with which people who lack certain home services become institutionalized, as well as the numbers of people with disabilities who lack these services. But it will not answer the question as to whether the continued ability to live in the community is required for meaningful access to health care. Once again, the idea that Alexander $v$. Choate confers complete discretion on states to determine what their benefit programs will include muddles the issue and thus must be moved out of the way.

\section{Debilitating the Legacy, Yet Again}

So we now address directly the need to deflate the misguided understanding of Alexander v. Choate by developing a substantive account of meaningful access. Developing a full account of meaningful access is not an easy task and it does not admit of a simple answer. It is far easier to explain why narrow readings of Alexander $v$. Choate are inadequate than to develop a fully fleshed out account of meaningful access. The account is not just a fuller set of standards for removing physical access barriers such as second floor offices that can only be reached by stairs or obtaining accessible medical equipment. It is also not an account of whether people with disabilities or anyone else lacks access to health care that would be optimally beneficial for them. But there is a great deal to say about how we might elucidate an account of what makes access meaningful.

In our earlier article, we used the concept of opportunity to put flesh on the idea of meaningful access: If benefits are structured in such a way that people with disabilities do not have the opportunity that others do to make use of them, access is not meaningful. An obvious example would be care that people simply cannot obtain at all because of the benefit structure to which they are subjected. Health care networks that do not include providers who can provide anesthesia to children, for example, would not offer children limited to these networks meaningful access.

Because of the interconnectedness of health care services, there are surely many examples of this type. Surgery that cannot be performed without a certain type of anesthesia, a minimum number of hospital days, or specified rehabilitation services is one kind of example. Services that must be performed in particular types of settings for legal or physiological reasons are another; examples are radiation therapy or treatments for infectious disease that require the professionals providing the service to be protected from exposure. In each type of case, without coverage for the condition on which the service is predicated, the service itself is prohibited and so there cannot be meaningful access to it.

But these are easier cases, and we now turn to the far harder task of explaining what it is that makes access meaningful. To do this, we note that several recent decisions of the Court in the area of education are particularly helpful in explaining what the language of this standard requires. So we start with cases from another area of law where the idea of meaningful access has been developed: access to public education for people with disabilities. Like health care, education is a good that is central to the ability to exercise opportunities. Unlike health care, education (at least in the early grades) is a good that has been publicly provided in the United States. But people with disabilities were left out, and Congress sought to address this with both the Rehabilitation Act, which applies to federally funded programs, and the Education of All Handicapped Children Act (now the Individuals With Disabilities Education Act (IDEA)), which requires a free and appropriate public education for all children with disabilities. As with the application of the Rehabilitation Act to state Medicaid programs, the court faced questions of this required with respect to access to education.

\section{Cases from Education: Exploring Substantive Standards for Meaningful Access}

Like health care, education is an important opportunity good. That is, it is a good that enables people to enjoy many other aspects of a good life, whatever that life is for them. Without education or 
even basic forms of health care, people will be unable to work successfully, communicate with friends and family, or participate in public life. So, it is not surprising that both have been provided publicly and that their inadequacy for people with disabilities has been condemned as disability discrimination. What is perhaps more surprising is that, with exceptions we detailed in our earlier article, there is a much richer set of cases involving education that do provide guidance about meaningful access than there is about health care.

Rowley v. Board of Education. Shortly before Alexander v. Choate was decided, the Court had faced the question of the services states were required to provide children with disabilities under the Education for All Handicapped Children Act (now IDEA, the Individuals with Disabilities Education Act) in order for them to receive a free and appropriate public education. This was the Rowley decision, ${ }^{19}$ handed down three years before Alexander $v$. Choate. Interestingly, although Rowley Court used the language of meaningful access, Rowley was not cited by the Court in Alexander v. Choate. Nor was Rowley cited in the Department of Justice brief filed on behalf of the petitioners claiming that Tennessee's limit violated the Rehabilitation Act. ${ }^{20}$ Perhaps the explanation is that Rowley was not litigated under the Rehabilitation Act, although it involved a public school that might easily have received federal funding. We will consider shortly whether the explanation might have been the assumption that the Rehabilitation Act and the IDEA are too different to be compared to each other with respect to the standards they require.

Amy Rowley was a deaf student with minimal residual hearing who sought sign language interpretation for her academic classes at school. Instead, the school offered her a special hearing aid and tutoring services. She contended that this enabled her to understand considerably less than other students in the same classes, despite her facility at lip reading. She performed better than the average student in her class and easily advanced from grade to grade- but was unable to achieve her full potential as she might have been able to do with sign interpretation. In ruling that Rowley was entitled to services "reasonably calculated" to provide her with educational benefit, ${ }^{21}$ the Court applied a "meaningful" access standard, ${ }^{22}$ which required states to "open the door of public education to handicapped children on appropriate terms [rather] than to guarantee any particular level of education once inside." 23

Like the language in Alexander $v$. Choate, this standard could invite interpretation along narrow access/content lines. Schoolhouse doors must be open; that is access. No particular level of education is required; that could be a rejection of content. But the door must be open "on appropriate terms", terms that make the access "meaningful." The stricture could lie instead against a "particular" guarantee. Once again, there is a gap: from the Court's rejection of the idea that Rowley was entitled to the educational services that would maximize her potential, it does not follow that all she was entitled to was an open schoolhouse door. There is much more to be said about how access and content are related here: the door is not open unless it is set ajar in a "meaningful" way "on appropriate terms."

Disability rights advocates were justifiably disappointed that Rowley did not receive the services that would have enabled her to realize her potential in the way other students could. There are well-taken arguments that the Court was wrong in concluding that Rowley had received educational services that did not violate the Rehabilitation Act's anti-discrimination mandate. Most importantly, the Court, in observing Rowley's progress, relied on her own skills in achieving despite the school's failure to provide interpreter services-a reliance not required of other students (Silvers 2009). She was thus not accorded an opportunity to achieve that was comparable to that provided to her peers. The Court mistakenly conflated this difference in opportunity with the equality of results standard it

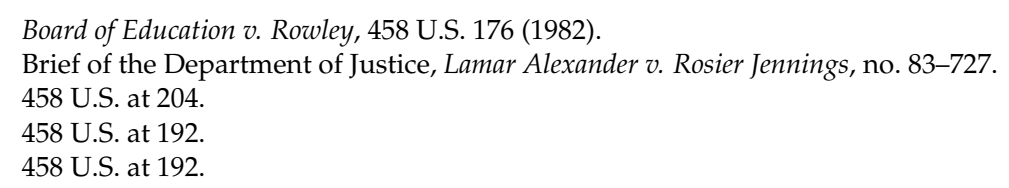


rejected. In what follows, however, we leave this larger question aside, because we think that there are other reasons why education cases provide useful material for making a start on understanding meaningful access. We now turn to explain why.

As Rowley was making more than adequate educational progress, further definition of the standard for educational benefit was not required to resolve her case. Over the ensuing years, courts fractured on how much was actually required of schools under the Rowley Court's language. Some courts interpreted the Rowley standard as "some benefit," others as "meaningful benefit," and still others as "effective" educational progress. The first of these interpretations was very minimalist, so minimalist as to put in question whether it allowed practices that were benefits in name only. The other standards, however, required more in ways that are enlightening for health care. To put the point we will develop briefly, these different approaches reflected different views about the extent to which the distinction between access and content collapses, because access, to be meaningful, requires significant content.

Endrew F. This last term, the Supreme Court finally confronted the question of the standard for educational benefit under IDEA. ${ }^{24}$ It decided the case in a way that is helpful to understanding meaningful access to health care.

Endrew $\mathrm{F}$ is a child with autism. His parents contended that the individualized education program (IEP) offered by his public school was inadequate because it failed to address behavioral issues that were impeding Endrew's ability to learn. When the proposed IEP did not change in this respect for several years, the parents moved Endrew to a specialized school for children with autism and sought reimbursement from the state for the tuition costs.

The issue in Endrew F. was the definition of the standard for determining when children with disabilities are "receiving sufficient educational benefits" to satisfy IDEA. In answering this question, the Court rejected both minimalist and maximalist accounts. The state had urged the minimalist approach of "some educational benefit that is more than de minimus." Their view was accepted by the agency and the lower courts in the case. The Court rejected this minimalist "some benefit" standard unanimously, reasoning that in Rowley they would not have needed to refer to the adequacy of the benefit if any benefit at all would suffice. ${ }^{25}$

On the other hand, the parents had urged, like the parents in Rowley, that the standard was an opportunity to learn equal to that afforded other students. Their view was that IDEA requires "an education that aims to provide a child with a disability opportunities to achieve academic success, attain self-sufficiency, and contribute to society that are substantially equal to the opportunities afforded children without disabilities." While this is a view that uses the language of opportunity, it incorporates an element of equality of outcome, requiring opportunities that would enable children with disabilities to achieve on substantially the same basis as children without disabilities. The Rowley court rejected such an equality standard as requiring unworkable comparisons and the Court in Endrew F. followed this reasoning. Courts, it said, are not equipped to make such judgments about whether children are achieving on a basis comparable to their peers. As we've said above, we think there are good grounds for challenging this reasoning. But there is still much to be drawn from the meaningfulness standard the Court did adopt.

In Endrew F, the Court adopted this standard: "a school must offer an IEP reasonably calculated to enable a child to make progress appropriate in light of the child's circumstance." ${ }^{26}$ Determining what is "appropriate" in this way requires an individualized assessment and educational program specially designed to meet the child's "unique needs" in light of "the child's present levels of achievement, disability, and potential for growth."27

\footnotetext{
Endrew F. v. Douglas County School District (22 March 2017),

Endrew F., slip op. at 10.

Endrew F., slip op. at 11.

Endrew F., slip op. at 12; italics in original.
} 
Delineating what makes progress appropriate in light of the child's circumstances is not easy, but the Court extracts from Rowley a number of factors to consider: whether the education is received (if possible) in a regular classroom, whether the student can receive the passing marks required to advance from grade to grade as measured by standard assessment tools, and whether the IEP sets out measurable goals that are designed to enable the child to be involved in and make progress in the general educational curriculum. ${ }^{28}$ For children who cannot achieve on grade level in the normal curriculum, educational progress must be "appropriately ambitious in light of his circumstances, just as advancement from grade to grade is appropriately ambitious for most children in the regular classroom." ${ }^{29}$ Although the Court does not articulate it, arguably a unifying thread lies behind these factors: the purpose of public education for all. Public education aims to provide people with basic elements of knowledge, the general curriculum. It attempts to do so in inclusive settings where children work together, the regular classroom. And it attempts to do so in regular stages throughout childhood, as students advance from grade to grade. Merely passing is not enough, either; they must advance in a way that is measured by standard assessment tools, which presumably measure progress of educational significance. Open school doors that do not do this for children do not provide them with education that is in any sense "meaningful."

This discussion of meaningful access in Endrew $F$. suggests that in considering meaningful access in health care we consider what the purpose is of providing public funding for health care through a program such as Medicaid. Like education, health care is a fundamental opportunity good. Without health care, people cannot learn, communicate, work, or live in the world. What health care people need to do this will of course vary appropriately with their circumstances. Some people will need vision aids, others mobility devices, and still others will need assistive communication. Some will need habilitation or rehabilitation. A sufficient number will need to be immunized to achieve herd immunity, and everyone will need access to simple preventive measures against likely health threats. There could, of course, be much more, but without, at least, measures such as these, access to health care will not be meaningful to people with these needs. It will be pointless, not just in the formal way in which someone cannot get surgery that requires 20 hospital days if she only has 14 , or in which someone may not recover from a raging infection if she is told she has a fever but is not provided the relevant anti-microbial. And it will not be "some benefit," as immunizations might be to someone who is institutionalized because she lacks a needed mobility device, who is then protected against infections transmitted from the institution's staff, visitors, or other residents.

This sketch draws analogies between the Court's discussion in Endrew F. and health care; however, there is more to be said about whether the two can be appropriately analogized.

Fry v. Napoleon Community Schools. Endrew F. is a decision under IDEA. As such, its application to the ADA and the Rehabilitation Act can at best be by analogy; comparisons may be problematic to the extent that the statutes have different goals and impose different standards-as, to some extent, they do. In a second important decision this term, the Court considered the interrelationship between these statutory schemes. In Fry v. Napoleon Community Schools, ${ }^{30}$ parents challenged a school's refusal to allow their child to bring her service dog to kindergarten. The school's position was that the dog's presence was not required by the child's individualized education program (IEP), which provided

28 In our view, these factors are ultimately insufficient. They could be met, for example, by poor schools in impoverished neighborhoods that provided limited opportunities for their students. This is the point made by disability advocates in criticizing Rowley. See, e.g., (Silvers 2009) Silvers, Anita. 2009. No Talent? Beyond the Worst Off! A Diverse Theory of Justice for Disability. In Disability and Disadvantage. Edited by Kimberley Brownlee and Adam Cureton. Oxford: Oxford University Press, pp. 163-99. Our point in using Rowley here, however, is that from the fact that a glass is half empty it does not follow that it is not half full-quite the contrary. As the Endrew F. Court recognized, there is far more substance to Rowley than many courts and commentators had recognized. This substance, we contend, is a starting point for reconsidering Alexander $v$. Choate in the way commentators wedded to the narrow understanding of the access/content distinction have failed to recognize.

29 Endrew F., slip op. at 14.

30 Fry v. Napoleon Community Schools (decided 22 February 2017). 
two-legged assistance for needs associated with the child's cerebral palsy. The parents' argument was that even if the student's IEP provided her with the required free and appropriate public education required by IDEA, the failure to allow her service dog denied her the reasonable modification she needed to allow her to participate fully in a public program - the school. The limited legal issue in the case was whether the parents needed to exhaust their IDEA administrative remedies before bringing suit. The parents contended that they did not, to the extent that they sought relief under the ADA or the Rehabilitation Act that was not available under IDEA. The school contended that because her request was school-related, compliance with IDEA procedures was required. In determining that exhaustion of IDEA procedures was not required, the Court considered the purposes of both statutes.

The Court's starting place in explaining the statutes was their remedies. Under IDEA, the remedy is what is required for a free appropriate public education; such an education is what IDEA demands. This requires an individualized assessment of the child's educational needs, measurable goals, and a plan for achieving these goals; the description in Fry foreshadows the decision several months later in Endrew F.

In contrast, the ADA and the Rehabilitation Act prohibit discrimination, including the requirement for reasonable modifications to enable enjoyment of the public service; for this proposition, the Court cited Alexander $v$. Choate. The remedies are injunctive relief against or damages for the discrimination. A school might discriminate even if it provided the student with fully adequate educational services; examples of such discrimination are requiring the student to use a catheter because the school did not provide an accessible bathroom, requiring a visually impaired student to be led by an aide rather than her guide animal, or requiring a mobility-impaired child to be carried rather than using her power wheelchair. Each of these is discriminatory even if it has no direct impact on the student's educational progress.

The "gravamen" of the complaint here was the discrimination-the failure to allow her what she needed to participate equally in a public program. Thus, the Court concluded, Fry's complaint was a core ADA/Rehabilitation Act concern, not one seeking the IDEA remedy. As one test for the difference, Justice Kagan suggested whether the lawsuit could have been brought by anyone visiting the school, rather than only by students. As another, Justice Kagan suggested asking whether the student could have brought suit in some context other than the school, such as a public recreation center or theater. That is, if someone other than a student could have sought the remedy, or if the student could have sought the remedy from an entity other than a school, the complaint is not seeking IDEA remedies in the way that would require exhaustion.

For our purposes in considering possible analogies between IDEA and the Rehabilitation Act, the question is whether this distinction between the statutory remedies has implications for comparing the ideas of meaningful educational benefit and of meaningful access to public programs under the ADA or the Rehabilitation Act. In this respect, the Court goes beyond the remedy sought, to the "gravamen" of the complaint. This is a substantive, not a procedural question; answering it hinges not on how the complaint is framed, but on how it fits within the purposes of the respective statutes.

One difference, not relevant to the understanding of meaningful access, is that the IDEA only covers children. Another, more relevant, is that the IDEA "guarantees individually tailored" education, whereas the ADA and the Rehabilitation Act "promise non-discriminatory access to public institutions." This language could be used to suggest that the ADA and the Rehabilitation Act have entirely different aims. One is substantive: education. The other is access: non-discrimination.

Once again, the access/content distinction might appear to be a bar, here to the analogy between education and health care. Once again, however, there is a gap in the reasoning. For understanding the significance of Fry in this way limits non-discrimination to access, construed narrowly. But that is exactly what is in question: whether access must be meaningful to those who pro forma have it. The Court in Fry recognizes this, for it once again qualifies non-discrimination substantively to require modifications needed for representatively replete, rather than unusually abridged or truncated, experiencing of the public service. 
In doing so, moreover, the Fry Court's strategy suggests its recognition of at least one kind of substantive differentiation. Note that the Court does not resolve the case by accepting contentions such as that the child's being catheterized and carried is equivalent to her executing the relevant bodily functions independently, despite the IDEA's directive to educate disabled children in the least restrictive environment. This suggests that the Court finds a substantive differentiation between the IDEA's and the ADA's standards of what nondiscriminatory access must provide. And when meaningful access is thus understood substantively, the access/content distinction collapses.

\section{Conclusions}

There is, of course, much more to be said about what makes access to various kinds of public services, and particularly to health care, meaningful. In this article, we've taken a first step in demonstrating why Alexander $v$. Choate should not be taken to reject the need for this inquiry. We've then used cases from education to suggest a starting point for health care in terms of the reasoning for the public provision of this care as an opportunity good.

Further elucidating this reasoning is critical to non-discrimination in Medicaid. An array of next steps suggest themselves. There is, for example, the National Council on Disability's testimony that provision of durable medical equipment, mental health care, prescription drugs, and rehabilitative and habilitative services are of special concern. In the last-named category, the National Council spotlights autism care, maintenance therapy, and limits on numbers of visits-in other words, services for individuals for whom the health care system offers chronic rather than curative care (National Council on Disability 2016). What is needed to make the protracted services appropriate for chronic, as distinct from curative, health deficits meaningful-whether this difference is a bright or a flickering line—calls for further investigation undeterred by the illusion that a clear access/content distinction can be maintained.

That health care needs for a particular health deficit are chronic signals the condition's potential for also being, or becoming, a disability, although experiencing enduring health deficits is insufficient to equate with disability unless disadvantaging social practices also obtain. The prospect of ACA alteration potentially affecting the availability of long-term health services prompts another pressing call for more profound understanding of reasonable, because meaningful as well as efficient, provision of chronic health care, especially because by their very nature chronic conditions challenge the imposition of short terms for care (Silvers 2012). In this article we have opened the way for such investigation by arguing that misreading Alexander $v$. Choate should not stand in the way.

Author Contributions: Professor Francis and Silvers worked together on the conceptualization of this article. The primary drafting and legal research were done by Professor Francis, with edits by Professor Silvers. Both authors take full responsibility for the contents of the article.

Conflicts of Interest: The authors declare no conflict of interest.

\section{References}

Bagenstos, Samuel. 2009. Law and the Contradictions of the Disability Rights Movement. New Haven: Yale University Press, pp. 69-72.

Baldwin, William. 2016. State Pension Funds: As Broke As Ever. Forbes (January 16) [online]. Available online: https:/ / www.forbes.com/sites/baldwin/2016/01/16/state-pension-funds-as-broke-as-ever/\#627713235738 (accessed on 15 September 2017).

Blake, Valarie K. 2017. Restoring Civil Rights to the Disabled in Health Insurance. Nebraska Law Review 95: 201-53.

CMS.gov. 2017. CMS Fast Facts. Available online: https:/ / www.cms.gov/research-statistics-data-and-systems / statistics-trends-and-reports/cms-fast-facts/index.html (accessed on 15 September 2017).

Crossley, Mary. 2014. Giving Meaning to "Meaningful Access" in Medicaid Managed Care. Kentucky Law Journal 102: 255-86. 
Kaiser Family Foundation. 2016. Exhibit 1: States have experienced historic declines in tax revenue during the Great Recession and have slowly improved. Available online: https:/ /kaiserfamilyfoundation.files. wordpress.com/2016/06/8883-exhibit-1.png (accessed on 15 September 2017).

Kaiser Family Foundation. 2017. Medicaid's Role in Nursing Home Care. Available online: http:/ /www.kff.org/ infographic/medicaids-role-in-nursing-home-care/ (accessed on 15 September 2017).

Minow, Martha. 1991. Making all the Difference: Inclusion, Exclusion, and American Law. Ithaca: Cornell University Press. National Conference of State Legislatures. 2013. State Balanced Budget Requirements. Available online: http: //www.ncsl.org/research/fiscal-policy/state-balanced-budget-requirements.aspx (accessed on 8 October 2017).

National Council on Disability. 2016. The Impact of the Affordable Care Act on People with Disabilities: A 2015 Status Report (16 January). Available online: https://www.ncd.gov/sites/default/files/NCD_ ACA_Report02_508.pdf (accessed on 15 September 2017).

Rosenbaum, Sara. 2015. Armstrong v Exceptional Child, Inc. Available online: http:/ /www.gwlr.org/armstrongv-exceptional-child/ (accessed on 8 October 2017).

Silvers, Anita. 2009. No Talent? Beyond the Worst Off! A Diverse Theory of Justice for Disability. In Disability and Disadvantage. Edited by Kimberley Brownlee and Adam Cureton. Oxford: Oxford University Press, pp. 163-99.

Silvers, Anita. 2012. Healthcare Justice for the Chronically Ill and Disabled: A Deficiency in Health Care Justice and How to Cure It. In Medicine and Social Justice: Essays on the Distribution of Health Care. Edited by Rosamond Rhodes, Margaret Battin and Anita Silvers. New York: Oxford University Press, pp. 299-312.

Snyder, Laura, and Robin Rudowitz. 2016. Trends in State Medicaid Programs: Looking Back and Looking Ahead. Available online: http:/ / www.kff.org/medicaid/issue-brief/trends-in-state-medicaid-programs-lookingback-and-looking-ahead/ (accessed on 15 September 2017).

The Kaiser Commission on Medicaid and the Uninsured. 2016. Medicaid Financing: The Basics. Available online: http:/ / files.kff.org/attachment/Issue-Brief-Medicaid-Financing-The-Basics (accessed on 15 September 2017).

Weber, Mark. Meaningful Access and Disability Discrimination: The Role of Social Science and other Empirical Evidence. Forthcoming. Available online: https://papers.ssrn.com/sol3/papers.cfm?abstract_id=3012118 (accessed on 15 September 2017).

(C) 2017 by the authors. Licensee MDPI, Basel, Switzerland. This article is an open access article distributed under the terms and conditions of the Creative Commons Attribution (CC BY) license (http:/ / creativecommons.org/licenses/by/4.0/). 